\title{
Elogio de la sencillez. Tratamiento de las pasiones en la gnosis de Clemente de Alejandría
}

\section{Praise of Simplicity. Treatment of Passions in Clement of Alexandria's Gnosis}

Daniel Vindas Sánchez

\begin{abstract}
Resumen
Este estudio propone analizar la invención de una gnosis basada en el elogio de la sencillez como una máxima del pensamiento filosófico y teológico clementino. El elogio de la sencillez está en la capacidad de la persona humana de hacerse divina; en este sentido, otra de las categorías que se desprenden de esta práctica es la de theoi andres, una categoría que logra sintetizar la filosofía pagana y el pensamiento cristiano de Clemente. La gnosis de Clemente no se comprende más allá de un sistema punitivo en torno a las pasiones, sino, más bien, como una serie de ejercicios de ética basados en el cuidado de la salud de la carne, la respuesta cristiana a la aristocracia y la pomposidad romana, así como el cultivo del sophron bios o vida temperante.
\end{abstract}

Palabras clave: Gnosis, teología clementina, filosofía pagana, tratamiento de las pasiones, uso de los placeres.

\begin{abstract}
This article proposes to analyze the invention of a gnosis that is based on the praise of simplicity understood as a maxim of Clement's philosophical and theological thought. The praise of simplicity is related to the capacity of the human person to become divine; in that regard another category which originates from this practice is that of theoi andres, a category that synthetizes the pagan philosophy and Clement's Christian thinking. Clement's gnosis is understood as a series of ethical exercises based upon the care of the flesh, the Christian response to the Roman pomposity and aristocracy, and the practice of sophron bios or moderate life.
\end{abstract}

Keywords: Gnosis, Clementine theology, Pagan Philosophy, Treatment of Passions, Use of Pleasures 


\section{A modo de proemio. La invención de una gnosis como administración de las pasiones}

La Antigüedad tardía se puede comprender como un terreno fértil para el renacimiento de las escuelas de pensamiento helénicas, no porque hubiesen desaparecido completamente, sino porque suponen nuevas categorías para pensar el mundo y el ser humano. Dentro de este terreno fértil, es posible hallar aquí y allá, un hervidero de significados. Pocas cuestiones son pasadas por alto en esta época, sobre todo si nos posicionamos en los primeros tres siglos, ahí donde la bonanza económica romana del siglo II se erguía ya lejana de la sociedad del siglo I, mucho menos enriquecida por los impuestos y el auge de los grupos terratenientes latinos.

Hablar de antigüedad tardía supone pensar una geografía del pensamiento que se extiende hasta los mundos exóticos que desembocan en el Norte de África, en ciudades como Cartago, Tagaste, Siria y el mismo Egipto, un mundo que se desarrolló culturalmente aún con la caída del imperio romano de Occidente, erguido bajo la figura oriental de Constantinopla y Bizancio. El griego predominaba en la escritura, el latín en el ámbito laboral, dejando en la figura del patronus o patrono, un personaje que llegó a encarnarse como metáfora ya del ser humano poderoso, ya del dios todopoderoso. De lo anterior se sigue que, a la altura del imperio romano-germano, Dios llegó a ser el patrono celestial del mundo feudal, destinatario de las oraciones tanto del campesino romano, de la mujer viuda, del mercader, del terrateniente y, por último, del obispo, el papa, y hasta el emperador. A las alturas del siglo II, el cristianismo sería visto como una amenaza digna de persecución por un delito de lesa majestad, es decir, atentar contra la naturaleza divina del emperador.

Dentro de las múltiples persecuciones, encontramos la de Nerón, en el marco del año 60 del siglo I, una persecución que pudo cobrar la vida de Pedro y de Pablo, con un aroma antijudío muy fuerte, así como una turbia diferenciación entre cristianos y judíos, sobre todo en esta primera generación de seguidores de Cristo; también está la del emperador Domiciano hacia el 96 d.C, la cual provocó la narrativa apocalíptica cristiana desde el deseo de un nuevo mundo o Basilea, es decir, el Reino de Dios como nuevo cielo y la nueva tierra. Esta cuenta también el cruento martirio de los cristianos a manos del emperador Trajano en el 110 d.C donde probablemente fue víctima Ignacio de Antioquía, uno de los padres apostólicos de la Iglesia. Luego de las brutales persecuciones a principios del siglo II, "La iglesia cristiana gozó de una completa tolerancia entre el 260 y el 302 d.C. Esta breve «paz de 
la Iglesia» tuvo una importancia crucial, como veremos luego, para la futura evolución del cristianismo en el Imperio romano" ${ }^{1 "}$, según el reconocido historiador Peter Brown. Sin embargo, aquella no fue la realidad que se vivió durante el siglo I ni durante el siglo II, donde encontraríamos a un Plinio el Joven denunciando, ante su emperador, precisamente el mencionado delito de lesa majestad cometido por aquel grupo que antes del alba cantaba alabanzas a Cristo como si fuese un dios.

Con todo, el cristianismo logró desarrollarse, y poco a poco fue tomando distancia del corazón del mundo judío, pues desde finales del siglo I y principios del II, el cristiano ya no solo era el judío sencillo, sino el helénico o el romano que podía labrar la tierra bajo las órdenes de aquel patrono, poco importaba para el terrateniente, el cristianismo del campesino, siempre y cuando labrara la tierra para sus intereses. En el siglo II ya es posible hallar una sociedad romana mucho más estratificada, la alta aristocracia aquí, el terrateniente allá, y la clase baja campesina, donde figuraban algunos cristianos. Uno de los triunfos del cristianismo fue la capacidad de llegar al corazón del terrateniente, tanto como al del campesino, desembocando en el mismo emperador: El cristianismo

1 Peter Brown, El Mundo de la Antigüedad Tardía. Prólogo de José Enrique Ruiz-Domenech y traducción de Antonio Piñero (Madrid: Gredos, 2012), 74 también se estratificó. Esto no sucedió, sin antes ver sendas disputas de los gobernantes en torno a los postulados cristianos, tanto la literatura herética como la pagana testificaron enconadas diatribas en torno a la filosofía y a la teología de la época.

Si el cristianismo se convirtió en una amenaza fue por su ética de vida asociada a la invención de una gnosis, algo extraña para la pomposidad romana; en este sentido, el cristianismo surgió como amenaza ante la idea de cómo ejercer el poder. La sencillez no era algo que le interesara demasiado a la aristocracia romana. Lo que se ha comprendido modernamente como vida privada era, en la antigüedad tardía, una red casi inseparable de la vida pública, vivida a menudo como una paradoja. Lo anterior se debía a que el ciudadano o el hombre civil se debatía entre una época movida por pasiones, por un lado, y el llamado a ser el hombre virtuoso, por el otro. De inmediato surgió el ideal del hombre bien nacido ${ }^{2}$, una manera de llamarle a quien ejercía un régimen en torno a su cuerpo, desde la gimnasia y la alimentación, hasta el uso de la pasión sexual.

A las alturas del siglo II, esta ética de los bien nacidos sería motivo de observación y de exhortación en

2 Peter Brown e Yvon Thébert, Historia de la vida privada. Tomo I. Imperio Romano y Antigüedad Tardia. Bajo la dirección de Phillipe Ariès y Georges Duby (Madrid: Taurus, 1990), 236. 
el compendio cristiano de ejercicios espirituales y de ética, pero lo problemático sería que un grupo religioso tan heterogéneo como el cristianismo integrara, dentro de sus ejercicios espirituales y corporales, aquella ética bastante secular y además reservada solo para los bien nacidos paganos. Nos encontramos ante el siglo II de la época antonina donde un Marco Aurelio denotaba aquel desprecio contra los cristianos que, según él, tenían prácticas parecidas a las de la secta del toro Mitra, basadas en lo maravilloso, el éxtasis y hasta en escenas orgiásticas.

Con todo, la antigüedad tardía posibilitó el intercambio, porque por otro lado muchos paganos optaron por la sencillez cristiana de vivir con lo necesario y construir una vida común sencilla. Lo anterior nos permite inferir que, dentro del paganismo romano convivía, a un tiempo, el bacanal perseguido desde el 186 a.C. y el ideal del bien nacido: aquella sociedad no era para nada homogénea en el uso de los cuerpos o de lo que en el helenismo se llamó chresis aphrodision o el uso de los placeres. Curiosamente, partiendo de la mirada de Marco Aurelio, más bien eran los cristianos quienes se daban a lo orgiástico, mientras que los romanos bien nacidos cultivaban un ideal de estoicismo con un sello muy antonino.
Así pues, la amenaza de la ética cristiana fue, en un principio, política en su sentido más amplio de la palabra, es decir, que promovía una forma de vida común donde no había "Ni esclavo ni libre, ni hombre ni mujer, ni pagano, ni judio" (Gal. 3,28) no porque aspirara a ejercer una religión de Estado, sino porque ejercía una forma de ejercer el gobierno de sí; en este sentido, el cristianismo fundó una suerte de micropolítica de la vida cotidiana que, con el paso del tiempo, se convirtió en macropolítica de Estado, no tanto porque fuera una consigna cristiana, sino porque fue una máxima pagana en boca de emperadores como Constantino, quien supo integrar estos elementos, de la vida cristiana comunitaria, a la política imperial de Roma. La amenaza cristiana no era militar ni económica, sino intelectual y ética, es decir, se presentó un conflicto sobre cómo debía manejarse el ciudadano cotidianamente, en torno a todas sus pasiones.

Por otro lado, la amenaza política, pues no había un ser más divinizado que el emperador, por lo tanto, aquel odio hacia los de Cristo desembocó en los martirios del papa Telesforo en el siglo II, junto al del ya mencionado Justino y un importante padre apostólico como Policarpo de Esmirna en 155 d.C. o el desgarrador martirio de Felicitas y sus siete hijos en 163 d.C. Los cristianos no mostrarían ningún levantamiento militar, como si lo habían 
hecho los judíos en tiempos de Nerón y Tito, quizá por eso el odio de algunos aristócratas paganos, por su similitud con los judíos, como lo fue el caso del historiador Tácito. Antes bien, las amenazas militares para Roma eran sus disputas internas, sobre todo después de la dinastía de los Severos hacia el siglo tercero y, por otro lado, en ese mismo siglo, el inicio de amenazas por parte de los partos y otros pueblos bárbaros.

\section{El hombre divino: La búsqueda del theoi andres como punto de encuentro entre la literatura clementina $y$ doctrinas filosóficas paganas}

En el terreno fértil de esta episteme germina un espacio no solo para la invocación a la piedad, la literatura apologética o la creación de dogmas dentro de lo que Celso llamó la Gran Iglesia, sino que también es un ambiente de ebullición carnal en un mundo todavía marcado por concepciones que han sido denominadas paganas. Uno de los fenómenos más emocionantes es la disputa entre la literatura cristiana y la literatura pagana. Ver a Celso trazando uno de los textos más antiguos en contra de los cristianos, pero ver también a un Orígenes respondiéndole al neoplatónico, no sin echar mano de la misma filosofía. La teología, poco a poco, se fue convirtiendo en una de las formas más elevadas de filosofía.
Ahora bien, el ancho imperio constituye mucho más que el centro de Roma y su pomposidad tanto intelectual como sociopolítica en toda su amplitud. El siglo II reúne un florecimiento de la sofística, una tercera etapa del estoicismo en su vertiente más ética, así como el neoplatonismo y el gnosticismo que vendrán a dar emocionantes disputas a otra vertiente no menos importante, la apologética cristiana. Si bien, el intercambio de saberes entre teología cristiana y filosofía pagana fue un hecho palpable, también son dignas de mencionar las fuertes diatribas que llevaron a la ejecución de algunos cristianos como Justino en el siglo II. A pesar de aquel intercambio supracitado, el estoicismo vio en el cristianismo un enemigo importante, al punto que el mismo Justino llegó a ser percibido como el gran traidor del estoicismo de la época, sobre todo para los filósofos más sobresalientes. Cada uno comenzaría a defender su verdad, y las disputas se dejaron ver en los escritos de un Celso, el filósofo neoplatónico, quien se refería a los cristianos como "una raza nueva de hombres nacidos ayer, sin patria ni tradiciones, asociados entre sí contra todas las instituciones religiosas y civiles, perseguidos por la justicia, universalmente cubiertos de infamia ${ }^{3 "}$.

3 Celso, El discurso verdadero contra los cristianos. Introducción, traducción y notas de Serafín Bodelón (Madrid: Alianza, 2009), 61. 
El antropomorfismo de Dios en un hombre como el Cristo era motivo de molestia y debate entre los paganos. Celso se llegó a preguntar qué necesidad tendría un dios de descender hasta la tierra de los vivientes ${ }^{4}$, y además de eso, ofrecer la redención a un pueblo predilecto y escogido ${ }^{5}$, acusándolos de falsa humildad. El neoplatónico también arremetió contra la idea cristiana de la resurrección y les acusó de plagiar los libros santos de otras religiones o filosofías paganas ${ }^{6}$.

Inmerso en este mundo de significados, símbolos y disputas encontramos la figura de Clemente de Alejandría (150-215), discípulo de Panteno ${ }^{7}$ y puede que del mismo Taciano ${ }^{8}$, seguidor de Filón de Alejandría y su método alegórico, y del estoicismo de la escuela de Musonio Rufo o Plutarco,

4 Celso, El discurso verdadero... II, 41. Traducción de Serafín Bodelón, 2009, 93.

5 Celso, El discurso verdadero... II, 44-45. Traducción de Serafín Bodelón, 2009, 95-6.

6 Celso, El discurso verdadero... III, 67-69. Traducción de Serafín Bodelón, 2009, 116-8.

7 Clemente de Alejandría, Stromata I. Conocimiento y religión. Introducción, traducción y notas de Marcelo Merino Rodríguez. Fuentes Patrísticas 7 (Madrid: Ciudad Nueva, 1996). "Al encontrarme con el último (en realidad era el primero por su capacidad) descansé tras haberle dado casa en Egipto donde estaba oculto. De Panteno, además, Clemente afirmaba que se encargó de engendrar una sincera y pura gnosis en el alma de sus discípulos. Strom I, 11,2, 91.

8 Peter Brown, El cuerpo y la sociedad. Los hombres, las mujeres y la renuncia sexual en el cristianismo primitivo. Traducido del inglés por Antonio Juan Desmonts (Barcelona: Muchnik editores, 1993), 175. sobre quien nos referiremos exclusivamente. Clemente elaboró un sistema de pensamiento a partir del cual se construiría una nueva noción de aquel logos platónico hacia el cual regresarán las almas en este mundo corruptible, así pues, entre aquel logos, elevado y divino de Platón, y el Dios clementino no habría ninguna distinción. Este theos agnostos o el dios desconocido sería accesible a través de la más elevada filosofía, de ahí la inquietud del alejandrino por comprender el gnosticismo, no tanto para repetir algunas de sus concepciones, sino para crear la suya propia. Por esta razón es plausible hablar de una gnosis clementina con un sello muy propio.

Todos aquellos maestros del teólogo alejandrino habían engendrado el carácter de aquel minucioso pensador del cual se conserva una parte importante de toda su obra, constitutiva del grueso compendio teológico del siglo II. Dentro de todas las enseñanzas que recibió, es posible argüir, con toda seguridad, que se encontraban los grandes maestros expositores del gnosticismo cristiano: los encratitas seguidores de Taciano, los gnósticos de la escuela de Valentín?.

Nuestro autor bebe de la época que porta la ética como bandera del estoicismo en su tercera generación, del neoplatonismo, de la prosa y de la

9 Brown, El cuerpo y la sociedad..., 177. 
retórica dentro de la Segunda Sofística, dentro de las cuales sobresale en la segunda mitad del siglo II la figura de Filóstrato y su Vida de Apolonio de Tiana $^{10}$, un taumaturgo digno de consideración dentro de los personajes del siglo, a menudo comparado con el mismo Cristo por sus atributos y capacidades casi divinas, dentro de las cuales se encuentran los milagros, las sanaciones y la vida piadosa, además de ser contemporáneo del Galileo en el siglo I. La mayoría de los comentaristas ven en Apolonio un pitagórico, piadoso, vegetariano y dado a la sabiduría, perseguido además por Dominiciano hacia finales del siglo I. Apolonio vivió entre el 3 a.C y el 97 d.C, había nacido en Tiana, en la ciudad de Capadocia y fue seguido por algunos que lo preferían como maestro antes que al mismo Cristo.

Un dato particular es el papel que jugó la emperatriz Julia Domna ${ }^{11}$,

10 Filóstrato, Vida de Apolonio de Tiana. Traducción, introducción y notas de Alberto Bernabé. Biblioteca Clásica Gredos 18 (Madrid: Gredos, 2008).

11 Filóstrato, Vida de Apolonio... Traducción de Alberto Bernabé, 2008, 15. Según Alberto Bernabé "en realidad es muy poco lo que sabemos de este círculo (kyklos) en la Vida de Apolonio, mientras que, en otro lugar, al mencionar a un tal Filisco, un sofista de Tesalia, nos dice que estaba unido a los "geómetras y filósofos que rodean a Julia". Por su parte, Dión Casio nos aclara que la emperatriz se había dedicado a diversiones intelectuales por la enemistad del poderoso prefecto de la guardia Fulvio Plauciano, que la excluía de las políticas. Si esto es así, el círculo se configuraría en los últimos años del siglo esposa de Septimio Severo, en la redacción de este opúsculo y su reputación de ser la promotora de un centro de estudio en torno al helenismo ${ }^{12}$, la taumaturgia y otros saberes arcaicos. La Vida de Apolonio de Tiana llegó a ser inspiración para el ideal del filósofo en pensadores paganos como Porfirio, acérrimo contrincante del cristianismo, así como la inspiración para Clemente de Alejandría y su modelo de Pedagogo. Dentro de los mismos usos del lenguaje que emplea Clemente, se encuentran los términos médicos antiguos cuando en su libro I del Pedagogo afirma que El pedagogo es un curador de $_{\text {pasiones }}{ }^{13}$, una forma de unificar no solo la medicina, sino la teología y la filosofía con la anterior. Una vacuna, una medicina, un antídoto son las metáforas del alejandrino para ofrecer su criterio de ingreso sobre el tratamiento de las pasiones. Esta analogía de la teología y la medicina se extenderá durante siglos, por ejemplo, para el siglo IV el Panarion de Epifanio de Salamina llegará a proponerse como el gran

II. La idea de este tipo de círculos de estudio aparece también en Clem. Al., Strom I, 20.

12 Clem. Al., Strom. I, 30, 1. Traducción de Marcelo Merino Rodríguez, 1996, 135. "Al igual que el ciclo de estudios, es útil para la filosofía, que es su reina, así también la misma filosofía contribuye a la adquisición de la sabiduría. La filosofía, pues, es una práctica de la sabiduría; la sabiduría, en cambio, es la ciencia de las cosas divinas y humanas y de sus causas".

13 Clemente de Alejandría, El Pedagogo. Introducción de Ángel Castiñeira, traducción y notas por Joan Sariol Díaz (Madrid: Gredos, 1998), III, 261. 
antídoto ante el veneno serpentino de la herejía. La relación entre un médico con un sacerdote es de origen pagano, pues el mismo Apolonio vivió en el templo de Asclepios, dios de la medicina, donde los sacerdotes del templo eran, a la vez, médicos.

Tanto el círculo de Julia, la emperatriz siria, como la Vida de Apolonio son acontecimientos coetáneos a la vida de Clemente de Alejandría, sobre quien se disertará en este trabajo. Según Alberto Bernabé: "Parece que Julia Domna trató de convertir a Apolonio en el prototipo de la fusión entre religión y filosofía que se opera en su época, y que le interesaba especialmente destacar en él su elevación de sentimientos, la pureza de vida y su piedad hacia lo divino ${ }^{14 "}$. Más que curiosas estas características admiradas en Apolonio por mostrarse tan cercanas al ideal del Padre de la Iglesia, en su ortodoxia de doctrina, santidad o pureza de vida y antigüedad apostólica o cercanía con los apóstoles. La mención del papel de Julia Domna ilustra muy bien que el ideal platónico del theoi ándres o el hombre divino está presente tanto en el paganismo como en el cristianismo de un Clemente. La misma fusión entre hombre sabio o filósofo y el cristiano estaba en el pensamiento clementino.

14 Filóstrato, Vida de Apolonio... Traducción de Alberto Bernabé, 2008, 16.
En Clemente hay una sentencia que subraya la idea platónica del theoi andres o el hombre divino, este es divino porque es bello, y ser bello es ser moderado y vivir en una armonía de las pasiones. La más grande de todas las ciencias será conocerse a sí mismo; porque quien se conoce a sí mismo conocerá a Dios ${ }^{15}$. Solo así el ser humano se convierte en Dios, según la interpretación de nuestro pensador cristiano. Este se convierte en Dios, porque lo quiere Dios. Recuerda también una cita atribuida a Heráclito: "Los hombres son dioses, los dioses, hombres" 16 . En Clemente, la carne es inmortal. Todavía estamos lejos de Nicea, del arrianismo y de la disputa por la naturaleza de Cristo y su sustancia.

\section{Armonía de los miembros corporales: EI uso saludable de los placeres y formas de vida común}

Los postulados que se plantean en este apartado se reúnen en la idea principal de que en el pensador alejandrino existe un régimen de vida común, una regla de vida anticipada a lo que será la Regula por excelencia en San Benito, Casiano, Aurelio Agustín, entre otros; sin embargo, hay que aclarar que en Clemente no hay estrictamente una regla monástica, sino unos hyponeumata o ejercicios de ética orientados hacia lo

15 Clemente de Alejandría, El Pedagogo, III, 261.

16 Clemente de Alejandría, El Pedagogo, III. Traducción de Joan Sariol Díaz, 1998, 262. 
cristiano. A partir de este primer postulado, se puede inferir que la apuesta por una vida común en Clemente debe comprenderse más allá de una hipótesis represiva; si se logra desmenuzar y comprender pieza por pieza su armazón teórica, se observa más un régimen de vida, o lo que en la antigüedad clásica se comprendió como chresis aphrodision, un uso de los placeres, asociado, en primer lugar, a la salud, a la armonía de los miembros corporales y a una dignificación del comportamiento humano, todo esto con el elemento cristianizado del Logos.

El otro elemento es la sencillez, quizá una relectura de la máxima paulina basada en un cristianismo donde no hay rico, ni pobre, es decir, existía una apertura hacia el hombre rico o el bien nacido pagano y hasta el esclavo. Clemente, "escribió con cólera genuina sobre aquellos que llamaban a los esclavos chasqueando los dedos: negarles a los esclavos el trato a través de las delicadas armonías de la voz humana era negarles su humanidad ${ }^{17}$ ".

La sencillez o népiotés, como se le conocía en griego, ilustraba un comportamiento sereno, pero a la vez jovial, donde la risa no era prohibida si armonizaba con la conversación e inclusive la ingesta de vino que apaciguaba el frío. Para aquel ideal de la sencillez, sería necesario, eso sí, ser

17 Brown, Cuerpo y sociedad ..., 180-1. como un niño. Aquella combinación entre los afectos infantiles y el estoicismo de un guerrero o boxeador eran el ideal perseguido por el cristianismo clementino. Se trataba de ser un gladiador que dominara sus pasiones y alcanzara un estado de apatheia.

Historiadores como Peter Brown han problematizado la comprensión moderna del estoicismo en tanto tratamiento de las pasiones, pues se trata de un término impreciso; las pasiones apuntaban a todo aquello que gobernara al ser y la apatheia no era un estado inerte de los sentimientos, sino una saludable administración. Lo que acá se entiende como las pasiones hace la salvedad contemporánea de que se trata de sensaciones, percepciones, deseos y hasta tentaciones, que experimenta un individuo de manera social y subjetiva y ante las cuales ejerce una ética. Si bien Brown entiende las pasiones casi como una suerte de concupiscencia de la carne, acá hace alusión a la conciencia de sí mismo, que implica tanto el pensar como el experimentar sentimientos.

Hablar de pasiones no implica estrictamente una práctica de excesos, el cristiano clementino era capaz de apasionarse, y quizá es acá donde se encuentra la sintonía con el historiador de la antigüedad tardía, sobre todo cuando dice que como criaturas físicas, los seres humanos, no podían evitar los 
"instintos ${ }^{18 "}$ (orexeis) o cuando se refiere a la sabiduría clementina como un proceso de formar una vida que no implicaba el castigo físico, mediante un acto que no exigía reprimir los sentimientos $^{19}$. Estos ejercicios de ética nos parecen lejanos a una cultura del cilicio, los flagelantes medievales o las penitencias, herederas de un estoicismo llevado a la radicalidad por las reglas monásticas.

En los Stromateis ${ }^{20}$, obra voluminosa del teólogo de Alejandría, es posible hallar una tesis contraria a lo que, por lo general, se piensa de la antigüedad tardía: que el cristianismo tomó muchas nociones filosóficas helénicas para su armazón y robustecimiento racional, antes bien, en la tesis de los tapices clementinos se plantea, ampliamente, la teoría de que fueron los griegos quienes copiaron la sabiduría hebrea, sobre todo en la figura mítica de Moisés. De lo anterior podemos inferir, para nuestro propósito contemporáneo, que hubo un intercambio de epistemologías sobre todo en la época del florecimiento helénico, a partir

18 Brown, Cuerpo y sociedad..., 184.

19 Brown, Cuerpo y sociedad..., 185.

20 El nombre original es Stromata, o bien Stromateis, en alusión a apuntes misceláneos o temas varios, traducido como Stromata de notas gnósticas sobre la verdadera filosofia. En estos cinco volúmenes, así ordenados modernamente, Clemente pretende, más bien, unificar su comprensión del gnosticismo con el cristianismo de la tradición apostólica o lo que él denomina la verdadera tradición por seguir el camino apostólico de Pedro, Santiago, Juan y Pablo. del siglo IV a-C y el ascenso al poder de Alejandro Magno. Esta teoría es ampliamente abordada en Stromata I, luego la retoma en el último tomo, es decir, el VII, sin embargo, no es una prioridad para este trabajo detenerse en detalles sobre si los hebreos copian a los griegos o viceversa. Es más sugerente pensar cómo estas dos vertientes, desde luego heterogéneas, llegaron a mezclarse de manera significativa, antes y durante el cristianismo.

El mismo Clemente toma un ejemplo arcaico para explicar este intercambio donde llama a los hebreos bárbaros en comparación con los griegos: "así como las Bacantes, que devoraron los miembros de Penteo, así también las escuelas filosóficas, la bárbara como la griega, recibieron una parte de cada una, aunque se gloríen de poseer toda la verdad"21. Lo que sí es digno de mencionar es que toda la escuela filosófica alejandrina bebe de la sabiduría arcaica de los egipcios, sabiduría que empapa el corpus clementino. De esta manera, Clemente es un puente entre el arcaico saber hermético egipcio recogido en Alejandría y el cristianismo del siglo II orientado hacia la gnosis, como mezcla entre fe y sabiduría:

Tales tenía origen fenicio, como se dice, y estuvo relacionado con los profetas egipcios; lo mismo que Pitágoras, quien se hizo circuncidar

21 Clem. A1., Strom, I, 57, 1. Traducción de Marcelo Merino Rodríguez, 1996, 203. 
por ellos para poder acceder a los santuarios secretos y aprender de la filosofía mística de los egipcios; y frecuentó igualmente a los Caldeos y a los Magos más distinguidos, y su vocablo homakoeion (asamblea común) significa oscuramente lo que nosotros llamamos hoy iglesia $^{22}$.

Clemente arremete contra los que exageran en torno a la inutilidad de la filosofía y exhorta a sus interlocutores a comprender a fondo los postulados filosóficos. La siguiente cita refleja cómo a la altura del siglo II, no solo existían las disputas entre las escuelas de pensamiento paganas y las cristinas, sino entre los mismos exponentes apologetas cristianos. Dice el alejandrino: "Yo quisiera añadir a mis detractores lo siguiente: en primer lugar, para suponer que la filosofía es inútil, al menos sería útil establecer la afirmación de su inutilidad. En segundo lugar, tampoco se puede condenar a los griegos solamente por la mención de las doctrinas que en ellos se contienen, sin penetrar a la vez hasta el fondo y descubrir su inteligencia"23. Con la mención de la cita anterior, se ilustra la disputa de Clemente frente algunos pensadores cristianos que él mismo denomina detractores.

22 Clem. Al., Strom. I, 66, 1. Traducción de Marcelo Merino Rodríguez, 1996, 217.

23 Clem. Al., Strom, I, 19, 1-2. Traducción de Marcelo Merino Rodríguez, 1996, 111.
La tradición mística hebrea entró inevitablemente en un diálogo complejo con la sabiduría clásica, Filón de Alejandría es un claro ejemplo de esta bella mezcla entre lo hebreo y lo helénico, pues él es judío, pero de gran inspiración cristiana para los primeros apologetas cristianos como Justino, Taciano y nuestro autor alejandrino. Es posible hallar en Filón un estoicismo todavía clásico en su estructura tripartita basada en la física, la lógica y la ética. Esta última es la que logró triunfar con más fuerza a las alturas del siglo II, y esa escuela estoica, así como la alegórica serán grandes influencias filonianas en la obra clementina.

Ya el siglo tercero, en la dinastía de los severos, vio germinar una época más que convulsa para Roma, mientras tanto el cristianismo seguía creciendo cautelosamente, no solo por la diversidad de sus personas adeptas, o por la lucidez de sus ideólogos, también filósofos, sino por su ética orientada a la vida pacífica y la comunidad. La comunidad ha sido el estandarte del auge del cristianismo. El elogio a la sencillez musita un estilo de vida en su totalidad emulada con aquella figura del galileo que, obviamente, dista mucho del pagano o campesino de los siglos II y III pues el de Nazaret era un tekton ${ }^{24}$.

24 Tekton es la palabra griega para un obrero calificado dentro de la polis, sin embargo, dentro de sus parábolas se refiere a metáforas que tienen que ver con el campo, cuando habla por ejemplo de las semillas en diferentes terrenos y lo que 
Ahora bien, no es una regla monástica lo que ofrece Clemente sino una ética cristiana para el ciudadano del siglo II, con la cual deberá comportarse en todos los ámbitos del mundo público y privado. Con lo anterior se sigue que es posible discernir en Clemente todavía, aquella máxima de la moderación o sophrosyne $e^{25}$ socrática, aquella armonía entre el cuerpo y el alma presente en el Fedón o en el Timeo de Platón, materializada en el gran ideal del cuidado de sí. Anterior a otros pensadores cristianos, y de la ya conocida regla monástica, todavía en Clemente, a pesar de su rigurosidad, existe un cuidado de sí. Un elemento crucial en Clemente es el elogio a la sencillez, a pesar de no ser de cuna pobre, emula la vida del galileo y su crítica ante los bienes materiales, en este sentido es posible rastrear ideas para una mística de vivir con lo necesario, no es una apología de la pobreza lo que hay en Clemente, pero con toda

puede recoger un sembrador dependiendo de su intención al sembrar.

25 Michel Foucault. Historia de la sexualidad IV. Las confesiones de la carne. Edición de Frederic Gros y traducción de Horacio Pons (España: Siglo XXI, 2019), 62. Foucault define la idea de sophron o sophrosyne como vida temperante, ante esto plantea que en Clemente existe la propuesta por la sophron bios o vida temperante, la cual no solo reúne la máxima de ser amo de sí mismo, no tanto para mantener el justo equilibrio y la necesaria jerarquía entre las facultades, como para asegurar el respeto, el pudor, la reserva reclamados por un semen que constituye el receptáculo de razones inmanentes a la naturaleza y que representa la oportunidad de una cooperación entre Dios y el hombre. seguridad tampoco una ética del vivir pomposo aristocrático característico del terrateniente romano o del emperador del siglo II. Por otro lado, dentro de su sistema ético es crucial comprender que nuestro autor reúne una ocupación por aquellas tres grandes manifestaciones de la animalidad humana sobre la cual se volvieron filósofos y teólogos: la comida, la bebida y el sexo.

Hablar de una communitas o comunidad nos podría acercar a un error de apreciación ontológica, que existe dentro de la vivencia de la vida común, una suerte de armonía celestial en la que todos se aman, se dan la paz y conviven felizmente. La idea de comunidad es conflictiva, y está llena de disidencias dentro de sí misma. El ejemplo mítico, por excelencia, dentro de la tradición judía es la rebelión de Lucifer dentro de la communitas comandada por Dios y su séquito de arcángeles. Esta comunidad cristiana mostró matices distintos a lo largo de la antigüedad tardía. Por ejemplo, a pesar de la bonanza económica dentro del imperio romano del siglo II, a lo interno del cristianismo varios grupos o facciones luchaban por ser el cristianismo ortodoxo o la Gran Iglesia, y este mismo siglo testifica, en la obra tanto de Ireneo como la de Tertuliano, una enconada disputa contra el marcionismo y las diferentes escuelas de un gnosticismo ya cristianizado. La imagen de Policarpo de Esmirna estrechando su 
mano con quien consideró la encarnación de Satanás refleja la naturaleza de una comunidad de disidentes dentro de sí misma, este semejante a Satanás no era más que el mismo Marción, cristiano adinerado que había donado una fortuna de dinero a la comunidad cristiana, y que, al final, terminó formando su propia facción de marcionitas. Dentro de la comunidad cristiana es posible ver a un cristiano llamando Satanás a otro cristiano, como en el caso de Policarpo a Marción, ambos cristianos, reflejo de una comunidad conflictiva. Lo mismo sucederá con Clemente y sus objeciones a un Taciano o Tertuliano, quizá demasiado sosegados, a la par suya.

Es posible observar en esta vida común del cristiano una característica de la animalidad humana, es decir, la capacidad de exterminio mutuo, que termina ya en la depredación, ya en la convivencia. El cristiano tuvo que aprender a convivir, al menos en los primeros tres siglos, con otros cristianos que se denominaban gnósticos, y no fue sino hacia el siglo $\mathrm{V}$ cuando el desprecio y la destrucción por lo pagano, llego a cobrar vida en manos de turbas como la que asesinó a Hipatía de Alejandría. Otra particularidad de Clemente, como autor cristiano, es la reflexión sobre la animalidad humana, en esto recuerda a Aristóteles. El cristiano de la antigüedad tardía logró formar una comunidad basada en la diferencia ontológica, ya vista desde la comunidad de Corinto en el siglo I, donde los mismos corintios disputaban entre sí, unos por ser de Apolo, otros de Pablo y otros de Cristo.

Hacia el siglo II, tal parece que el perfil del cristiano era el del liberto, aristócrata exitoso, más o menos acomodado con su mujer y familia, pero a menudo carente del gran saber pagano. Es interesante plantear que el cristiano se yergue a partir de un saber filosófico que le da pertenencia, los cristianos tienen su propio saber-poder en boca de hombres como Clemente, que hacen de modestos en el fondo de su erudición y plantean una vida regida por un paidagogo de la sencillez llamado Cristo. Un poco de cristianismo estoico, pero también de estoicismo ya cristianizado, con ideas arraigadas del zoroastrismo y su creencia en demonios que acercan al ser humano a la amentis, es decir, a la demencia, una pérdida de $\mathrm{sí}^{26}$. El cristiano ya no será

26 Celso, El discurso verdadero... III, 65. Traducción de Serafín Bodelón, 2009, 115. Las divisiones entre cristianos era algo que ilustraba Celso con especial atención, se refería a aquellas facciones como sectas dentro de las cuales se encontraban "sibilistas, los simonianos, y entre estos los helenianos del nombre Helena o Helenos, su maestro; los marcelinianos, de Marcelina; los carpocratianos, salidos unos de Salomé, otros de María, otros de Marta; los marcionitas nútranse de Marción; otros incluso se imaginan unos a tal demonio, otros a tal maestro, aquellos a tal otro, y se sumergen en espesas nieblas, se entregan a desdenes peores y más ultrajantes aún para la moral pública que aquellos que, en Egipto, practican los compañeros de Antínoo". 
más un tonto, será conocedor, pero sencillo. Será gnóstico, porque se abre al conocimiento, y será divino (theoi andres), porque practica la sencillez.

En su voluminosa obra sobre la antigüedad tardía, Peter Brown plantea un debate sobre la noción de decadencia en los primeros siglos del cristianismo, que llevan hasta la caída del Imperio Romano en el siglo V. Esta decadencia nunca fue tal, diría el historiador irlandés, toda vez que aquellas escuelas de pensamiento se mantuvieron vivas, resucitaron-si se quiere-con el nacimiento, desarrollo y auge de la teología cristiana. Se puede afirmar que el auge romano permaneció a nivel cultural y solo feneció a nivel de sus estructuras políticas en las sociedades occidentales, y aún en la antigua Constantinopla sobrevivieron bajo el esquema de República: "Incluso en los estados bárbaros del occidente de Europa durante los siglos VI y VII, el Imperio romano, tal y como sobrevivió en Constantinopla, era aún considerado como el estado civilizado más importante del mundo" 27 . No es preciso, en este momento, detenerse en estas tesis históricas; sin embargo, es necesario apuntar la conflictividad dentro de la cual nos encontramos a la hora de estudiar esta época tan fértil en el terreno de la historia del pensamiento. "La integración de la filosofía en

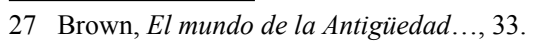

los primeros escritos de literatura cristiana no fue un intercambio del todo amigable, pues el ideal de las nuevas sociedades romanas, sobre todo en torno a su idea de aristocratización, viene añorando el ideal del hombre de las musas, es decir el varón que cultiva la sabiduría clásica"28. Hemos demostrado hasta acá, cómo el ideal del ser humano bien nacido se confundía entre el estilo pagano estoico y el cristiano seguidor de Clemente.

\section{Añade Brown:}

Así pues, tenemos dentro del Imperio a romanos no cristianos que persiguen un ideal helénico, pero también con toda seguridad a romanos cristianos que hacia el siglo IV aseguran tener una suerte de Gnosis cristiana, de ortodoxia y de saber bajo la fórmula de un método basado más en la sencillez que en la erudición. Juliano el Apóstata (361363 ) creía sinceramente que su hermano Galo se había «transformado en un salvaje», mientras que él, por su parte, había sido «salvado» por los dioses, quienes le habían otorgado una educación universitaria ${ }^{29}$.

La afirmación de Brown sintoniza con el caso concreto del pensamiento de Clemente de Alejandría, quien veía en su tipo de cristianismo una forma de gnosis; sin embargo, es posible hacer una crítica de

28 Brown, El mundo de la Antigüedad..., 43.

29 Brown, El mundo de la Antigüedad..., 43. 
la cita anterior, sobre todo cuando Brown afirma que existió una gnosis cristiana hacia el siglo IV, lo cual es inexacto, si se toma en cuenta el auge gnóstico de los siglos II y III. Brown ubica la gnosis cristiana de manera muy tardía en su ejemplo. Lo anterior se demuestra con una lectura de los maestros gnósticos de Clemente y, desde luego, a través de sus Stromata. Este ideal de un Juliano ${ }^{30}$, de percibir a los cristianos como salvajes pudo haber bebido de tradiciones críticas del cristianismo, tanto en el ya mencionado Celso como el mismo Porfirio de Tiro en el siglo III.

\section{Una communitas orgiástica: Gnosis, sexualidad y formas de vida común}

Ciertamente, es posible hallar en el cristianismo una forma de gnosis. Brevemente, la doctrina gnóstica ${ }^{31}$ está

30 Juliano, Contra los galileos. Cartas y fragmentos. Testimonios. Leyes. Introducción, traducción y notas por José García Blanco y Pilar Jiménez Gazapo (Madrid: Gredos, 1982), 15-50. Para Juliano, conocido como el apóstata, los cristianos solo testifican sobre un Dios cuya envidia se refleja en el acto egoísta de privarlos del conocimiento primordial simbolizado en aquel árbol edénico. La serpiente, para Juliano, probablemente influenciado por tradiciones antiguas a él, más bien era una bienhechora y portadora de conocimiento y libertad.

31 Para un estudio más detallado sobre el gnosticismo se puede consultar la obra de Ireneo de Lyon, Adversus Haereses, probablemente uno de los testimonios más concretos antes del basada en una opinión cosmológica que problematiza la idea de Dios y del ser humano, de este mundo hílico y el espiritual, de lo pecaminoso y lo legal. Lo cierto es que este mundo es imagen imperfecta de una contradicción eterna, pues el Uno o increado en sus emanaciones divinas sufre una rebelión cósmica, se trata de la Sophia o Sabiduría, a menudo comprendida como una divinidad femenina o al menos como un aspecto femenino de la divinidad. El gnosticismo es neoplatónico desde el punto de vista de su búsqueda trascendental y del predominio de un gobierno, más no desprecio, del alma sobre el cuerpo.

Sophia vive en una angustia constante, combinada con un delicioso placer terrenal. La angustia primera es por no encontrar la forma de volver a ser totalmente espiritual, y la satisfacción es por lograr lo que tanto anheló, alcanzar la finitud y la sensación de lo carnal. Acá es donde aparece el Demiurgo, un dios o Creador que es bueno, pero no

corpus clementino. En el libro I, el autor ofrece un resumen de la doctrina gnóstica. También se puede consultar el tomo I de los gnósticos a cargo de J. Montserrat Torrents, donde viene además el libro I de Ireneo, en José Montserrat Torrents, Gnósticos I, Biblioteca Clásica Gredos, 59 (Madrid: Gredos, 1983), 77-215. También de José Montserrat Torrents, Gnósticos II, Biblioteca Clásica Gredos, 60 (Madrid: Gredos, 1983). Otro compendio más actualizado ha sido editado por Antonio Piñero, José Montserrat Torrents y Francisco García Bazán, Textos Gnósticos. Biblioteca de Nag Hammadi I. Tratados filosóficos y cosmológicos (Madrid: Trotta, 2007). 
perfecto como aquel Uno Increado, inalcanzable, theos agnostos e inefable. Este demiurgo será comparado por los gnósticos como el mismo Yahvé o el mismo Dios del Antiguo Testamento, lo cual enfurece a Clemente en contra de Marción y los valentinianos por mantener esas creencias. El gnosticismo de estos dos últimos exponentes nos permite pensar, aún dentro del cristianismo que Dios no es perfecto, ni autosuficiente, ni todopoderoso, sino que quiere ser carnal, sexual, y hasta femenino, una herejía como esta no sobreviviría mucho y, precisamente, así fue. En parte, gracias a los Stromata $^{32}$ clementinos tenemos información de estas herejías, que, a pesar de ser refutadas, ofrecen también datos de su existencia.

El gnosticismo clementino radica en la idea del cristiano culto, no solo en el campo del saber sino en el de la ética de vida. El ideal del theoi andres o el hombre divino es una de las características medulares del corpus clementino. El retorno a la divinidad anhelado por los gnósticos es recogido por Clemente y llevado a la práctica no solo mediante la sencillez sino por el camino de la continencia en todos los ámbitos. El hombre divino es el que se gobierna a sí mismo: "es puro y paciente, vive

32 Clemente de Alejandría, Stromata II-III. Fuentes patrísticas 10. Conocimiento religioso y continencia auténtica. Introducción, traducción y notas de Marcelo Merino Rodríguez (Madrid: Ciudad Nueva, 1998). conforme a justicia, domina las pasiones, da de lo que tiene y, tal como es, beneficia y de palabra y de obra" 33 .

Acá hay que precisar dos aspectos, que el hombre divino en Clemente dista mucho del hombre divino dionisíaco, dentro del cual podemos recordar la frase célebre de las Bacantes de Eurípides en boca de Dioniso o el Extranjero: he trocado la figura del dios por la humana, sin embargo, como veremos más adelante, tampoco se trata de un hombre ajeno a la fiesta, o que reniegue totalmente de la carne. En esto radican las disputas de Clemente con el gnóstico Taciano, que veía en este mundo solo ocasión para el mal, creado por una divinidad maligna y, por lo tanto, dejando ver en la carne lo malo, perecedero y despreciable. Así pues, existe un gnosticismo que practica un enconado desprecio del mundo, a la par del de Clemente que ve, en este ámbito terrenal, la capacidad de dignificar el cuerpo mediante su régimen saludable de vida. Solo los dos ejemplos anteriores testifican la complejidad y conflictividad dentro de la communitas cristiana.

El gnosticismo es lo suficientemente amplio, diverso y denso, filosóficamente, como para tratarlo en una sentada; lo cierto es que se ha revelado armonioso con la escuela neoplatónica

33 Clemente de Alejandría, Stromata II, 97,1. Traducción de Marcelo Merino Rodríguez, 1998, 231. 
del siglo II que vio un auge bastante significativo dentro de la Antigüedad tardía, compartiendo la mesa cotidiana del banquete filosófico con escuelas como la estoica. La vida común del gnóstico, basado en un logos preexistente, armoniza ya en el evangelio de Juan, ya en la obra de Ireneo, y en la de Clemente. Para Clemente, y para el gnóstico común, Dios mismo es una comunidad, aunque no hable estrictamente de una trinidad, al estilo temprano de Tertuliano o al estilo voluminoso y minucioso de Aurelio Agustín en su De Trinitate.

El logos materializado en la humanidad de Cristo es una forma de pensar que dentro de la divinidad existe una humanidad intrínseca, pero que también dentro de lo humano viene ya destilado el destello de lo sagrado, esto para un judío promedio, por ejemplo, podía ser una blasfemia, porque o se es dios o se es humano. Definitivamente, la idea de que la humanidad puede ser divinidad a un tiempo proviene de Platón y sobre todo del gnosticismo. El gnóstico añora volver a hacerse divino, ahí en su aparente desprecio de lo carnal, hay un reclamo por la unión entre lo humano y lo divino. El gran debate por la resurrección de la carne, la salus carnis, está en el libro V de Ireneo. Si se resucita con carne o no, es un tema del siglo II, pero que no deja de ser una incógnita para el ser cristiano actual. Ireneo, en sintonía con Pablo, afirma que se resucita con un cuerpo, y que se va al castigo eterno o al paraíso con un cuerpo espiritual. De lo anterior, se sigue que el cuerpo también es una comunidad, y esta es la comunidad que le apasiona a la nueva filosofía cristiana. El cuerpo imperecedero también continuará en las posturas de Aurelio Agustín, quien planteará el paso de un cuerpo corruptible a un cuerpo incorruptible.

Pues bien, ante la pregunta fundamental sobre la teología, que integra, desde luego, a la filosofía, nos encontramos la respuesta de que la ciencia de lo theos nace como una ocupación ante la pregunta constante de qué hacer con las pasiones. Antes de repetir el discurso predominante sobre el cristianismo como represión, renuncia sexual, recato moral y espiritualización del cuerpo, es necesario tomar postura, para lanzar una crítica recurrente que se da dentro de la academia. El cristianismo como forma de vida común, como koinos bios, ofrece más bien un esquema rizomático de las relaciones carnales. Aclaremos, no quiere decir que no existieran fracciones que practicaban la enkrateia o un abandono más marcado del cuerpo; sin embargo, se quedaría corta esta apreciación sobre el cuerpo y sus despliegues dentro de la ética cristiana.

Se puede imaginar a Pablo dando sentencias sobre la bebida en una 
época en la que también Plutarco dictaba sus charlas de sobremesa, sus Quaestiones convivales. Qué hacer con las pasiones es uno de los temas representativos, no solo de la filosofía, sino de la teología. Es posible encontrar a un autor prolijo como Galeno, a un tiempo filósofo y médico, y su ocupación por todos los fluidos humanos, quizá después de Sorano y su tratado sobre ginecología, tenemos aquel famoso volumen sobre el semen o la semilla. Dentro del mundo cristiano, Pablo ofrece no solo un tratado sobre el matrimonio, sino unas primeras instrucciones sobre la vida sexual, donde exhorta a la enkrateia en lugar de la porneia. Estas influencias serán citadas a menudo en la obra de Clemente, donde la vigilancia de la carne será crucial para el cristiano saludable.

En Stromata III, se vislumbra un hallazgo muy rico dentro de la literatura cristiana, porque ofrece no solo una discusión con los encratitas, sino que también permite obtener información de las diferentes facciones gnósticas. Por ejemplo, del gnóstico Valentín, tenemos que fue discípulo de Teudas, quien lo fue a su vez de Pablo. El distanciamiento de Valentín con el papado del siglo II fue por la negativa de aquellos a nombrarlo papa; sin duda, un eventual nombramiento papal de Valentín hubiese sido crucial para el rumbo del cristianismo. Valentín es tan antiguo como Ireneo, ambos un poco mayores que Clemente, y ofrecen una buena cantidad de información filosófica y teológica del cristianismo primitivo después de Pablo y los apóstoles.

Del gnosticismo, Clemente discurre ampliamente, dejando ver creencias que van desde la vertiente más espiritualista, hasta opiniones muy sugerentes como el aspecto andrógino de Dios, sobre todo en los discípulos de Valentín. Es sabido que ya en los babilonios existía esta interpretación andrógina de la divinidad. Dentro de los referentes del gnosticismo, encontramos a Simón el Mago, un taumaturgo comparado con Cristo, al mismo Valentín, a Basílides y, por último, a Carpócrates y su hijo Epífanes. Los carpocratianos, una doctrina bastante escondida dentro de la tradición e inclusive del estudio del gnosticismo, fue fundada por estos dos últimos gnósticos mencionados, ante los cuales Clemente arremete por tener la creencia de compartir las mujeres entre los integrantes de su comunidad. Además, aquel ideal del theoi andres llevo a Epífanes a ser adorado como un dios, es decir, todo lo contrario, a la idea clementina de la sencillez. En Epífanes encontramos el ideal del hombre divino llevado a la radicalidad, si se quiere, a la idolatría: "le construyeron y le tallaron un templo de piedra tallada, altares, tabernáculos y un museo; y los cefalonios se reúnen en el templo en período de luna llena a para ofrecer sacrificios a Epífanes en el aniversario 
del día de su nacimiento divinizado, y realizan libaciones y banquetes, y le cantan himnos" 34 .

Esta idea carpocratiana de vida común es llevada también a la radicalidad, mediante sus propias lecturas de los textos bíblicos, sus propios criterios filosóficos y su auténtica ética de vida. Para Epífanes, la comunidad es tomada muy en serio, donde la justicia de Dios es una especie de comunidad igualitaria $^{35}$, y además se acuñan al pie de la letra los postulados paulinos que no hacen distinción entre hombre y mujer, esclavo o libre, rico o pobre, necios o cuerdos. En la comunidad carpocratiana, la ley solo engendra transgresión y su ética es una justicia innata, es decir, es una comunidad que se autoabastece.

En lo referido a la concupiscencia, la creencia carpocratiana disiente con la clementina, pues, al contrario de lo planteado por esta, aquella otra ve en la concupiscencia una forma de conservación de la especie, vista inclusive como mandato de Dios ${ }^{36}$. Los grupos carpocratianos se reunían, hombres y mujeres juntos, más en honor a la diosa Venus que a Dios. Añade Clemente,

34 Clemente de Alejandría, Stromata III, 5,1. Traducción de Marcelo Merino Rodríguez, 1998, 323.

35 Clemente de Alejandría, Stromata III,6,1,2,3,4; 7,1. Traducción de Marcelo Merino Rodríguez, 1998, 323.

36 Epífanes, Frag., 1. En Clemente de Alejandría, Stromata III, 8,1,3. Traducción de Marcelo Merino Rodríguez, 1998, 327. sobre estas reuniones, que no son dignas de llamarse eucaristía: "Dando media vuelta a las lámparas, quitan del medio aquella luz que desenmascararía su justicia impúdica, y se juntan como quieren y con quien desean... pero estas leyes las debería haber impuesto Carpócrates, pienso yo, a la lascivia de los perros, los puercos o de los machos cabríos" ${ }^{\prime 3}$.

Las alusiones a lo orgiástico no solo están presentes en las diatribas clementinas, sino al contrario, algunos emperadores como el mencionado Marco Aurelio o el mismo Celso condenaban a los cristianos de darse a escenas orgiásticas. Por otro lado, la alusión al macho cabrío, en especial, remite a los rituales del satyricon en la antigüedad clásica, o a la noción de tragodon que no es más que la tragedia como el canto del macho cabrío o el canto por el macho cabrío. En el cristianismo del siglo II existe una reminiscencia por lo trágico y lo orgiástico en los carpocratianos con la inclusión de lo festivo y del sexo, y en Clemente, también con lo festivo, pero como gozo de la carne ante el único Dios y no el culto a la concupiscencia.

Clemente hereda la antropología pensada por los estoicos basada en el cuerpo como una armonía, por eso a menudo los nervios son comparados

37 Clemente de Alejandría, Stromata III, 10,1. Traducción de Marcelo Merino Rodríguez, 1998, 331 . 
con las cuerdas de una cítara. Con un estilo que recuerda la ética socrática o algunos postulados platónicos, se ocupa de aquellos movimientos del cuerpo que podían afectar el alma. Aquel sopor del sueño se asemeja a la muerte, de manera que como era la costumbre antigua, el dormir es morir un poco, pero más allá de esto, el buen dormir estará asociado al buen comer. Quien come sano dejará entrar sueños lúcidos, por ejemplo, Clemente utiliza la metáfora hijos de la verdadera luz, lo cual hace pensar, en el evangelio de Juan, una idea de origen gnóstico.

\section{Un demonio del vientre: El uso de la gastromarguía entre el cuidado de la salud y el temor a la concupiscencia}

Sobre la relación del comer y el dormir dirá el alejandrino: "los eructos cargados de vino, los ronquidos de los que han comido opíparamente, los silbidos de los que están envueltos entre las mantas, los rumores de los vientres atascados abruman el eje lúcido del alma, mientras que la mente se llena de infinitas alucinaciones" ${ }^{\prime 38}$. La armonía entre cuerpo y alma, ya socrática, ya estoica, se deja ver como herencia ética en aquella economía de gestos, fluidos y hasta flatulencias, lo cual también nos hace recordar al mismo Hipócrates. Cada movimiento del cuerpo es

38 Clemente de Alejandría, El Pedagogo II, 81, 1, 2. Traducción de Joan Sariol Díaz, 1998, 218-9. detalladamente sometido a examen de conciencia: reír, comer, eructar, roncar, todo aquello podía señalar, no un pecado o un mal gesto ético, sino una falta de armonía en la salud de la carne. En la communitas clementina predomina más el ideal de una armonía saludable de las pasiones que una mortificación represiva del sexo.

El arte de comer será recatado, cada movimiento será como milimétrico en Clemente, desde cuándo mojar el pan en el plato, hasta si es oportuno sonarse o no la nariz. Mucho menos estornudar porque genera una mueca semejante a las máscaras de la tragedia ${ }^{39}$, lo mismo con el deglutir del alimento, que no conozca deformación alguna, no hacer muecas ni en el momento de la deglución ${ }^{40}$. $\mathrm{Ni}$ que decir del bostezo, que indica signos de un espíritu débil. El rostro para el alejandrino debe conservar la medida en su gestualidad, pues cualquier

39 En Clemente de Alejandría, El pedagogo II. Traducción de Joan Sariol Díaz, 1998, 1989. Una demostración casi pitagórica, sino platónica de la armonía de los fluidos. Eructos, escupitajos, hasta estornudos angustian el estoicismo clementino de consumar un orden del comportamiento del cuerpo. El estornudo, por ejemplo, no solo es escandaloso, sino que lleva a la persona a hacer una mueca, dirá Clemente "sin emular las máscaras trágicas, abriendo la boca de par en par, además del ruido que genera el estornudo, el exceso de aire que se emana, el cual podrá dejar escapar como dice el alejandrino las mucosidades que tal vez la fuerza del aire congregó".

40 Clemente de Alejandría, El Pedagogo I. Traducción de Joan Sariol Díaz, 1998, 151. 
ademán podrá ser ocasión de atentar contra esta armonía del cuerpo y aleja del logos, es duro cuando critica a quienes están jadeantes de intemperancia porque depositan y empujan deprisa y confusamente los alimentos en el vientre ${ }^{41}$. Cualquier norma pomposa de etiqueta gastronómica tiene un asidero teológico.

La etiqueta clementina es estoica cuando se preocupa por la salud, y pomposa cuando aspira hacia la aristocracia romana. El cristiano nuevo será vigilante en el comer, no en demasía para no fomentar la locura o la gastromarguía, una suerte de concupiscencia del estómago, una intemperancia del apetito, lo mismo pasará con la bebida, símbolo del Logos por un lado, pero de la perdición por el otro, porque quien padece la demencia del estómago no solo padece una enfermedad del cuerpo sino del alma: "En cuanto a los que se inclinan sobre las mesas humeantes, como si amamantaran sus propias pasiones, tienen por guía un demonio muy glotón, al que yo no me avergonzaría de llamar, 'un demonio del vientre'; éste es, sin duda, el peor y el más funesto de los demonios. Ese tal se asemeja a un ventrílocuo"42, sentencia Clemente. Este tipo de interpretaciones se pueden observar ya en San Antonio, de quien el demonio

41 Clemente de Alejandría, El Pedagogo I. Traducción de Joan Sariol Díaz, 1998, 150.

42 Clemente de Alejandría, El pedagogo I. Traducción de Joan Sariol Díaz, 1998, 155. consigue también llevarlo a la mortificación de la angustia por la carne. Clemente mezcla, aquí y allá, la creencia arcaica en aquel demonio ventrílocuo, y la ética de la salud estoica. En una pintura que lleva como nombre "El tormento de San Antonio", de Miguel Ángel (1487), la cual es una versión a color de un grabado del alemán Martin Schongauer (h.1470), se ilustran, jocosa y coloridamente, todas las clases de tormentos del monje contra sus propias proyecciones, quizá aquellas mismas alucinaciones de las que hablaba Clemente, unas por demasiado exceso de pasión en el comer, otras por demasiado exceso de pasión en los ayunos; hay, por otro lado, pinturas en las que al eremita San Antonio, los demonios le jalan la barba y hasta las partes pudendas.

La persona comilona es similar a la airosa, porque entra en locura, lo cual no solo daña el cuerpo, sino que atenta contra la vida común que propone el cristianismo, esa gastromarguía, como su nombre lo indica, es un delirio del estómago, ya que márgos significa "lo-

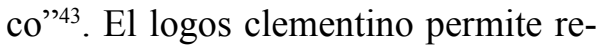
cordar la filosofía socrática, ya presente también en Pablo, luego en la mayoría de los estoicos, en la búsqueda de esa justa medida de las pasiones. En ningún tratado se habla estrictamente de represión, sino de ocupación y cuidado

43 Clemente de Alejandría, El pedagogo I. Traducción de Joan Sariol Díaz, 1998, 150. 
de sí. Quisiera detenerme un poco en esta noción de gastromarguía, porque permite detectar otro elemento inédito dentro del cristianismo en Clemente, el cual permite ampliar no solo la idea de un elogio a la sencillez, sino una crítica a la pomposidad aristocrática de su época. En un mundo tan marcado por las desigualdades, el ser cristiano es llamado a la sencillez, lo cual implicaba que una persona adinerada se despojara de sus bienes en algunos casos, como el caso de Cipriano de Cartago, otro pensador cristiano, ilustrativo para la tesis que se plantea acá, pues de familia adinerada, al convertirse, dona sus bienes a la comunidad cristiana.

Esta idea de comunidad clementina permite pensar que todo es de todos, y que los cristianos se sostenían como en un principio lo hicieron aquellos judíos que creían en la sencillez del Galileo. En los siglos II y III, el sistema tributario era rígido y un campesino a diario trabajaba arduamente para recibir muy poco. Dentro de la comunidad clementina, el terrateniente estaba llamado a encarnar el ideal del hombre sencillo. Clemente, sobre todo en El pedagogo, le habla a personas de corte pagano que se acaban de convertir, y que tendrán que aprender a vivir en comunidad, por eso esa idea de comer o beber lo necesario, porque la mesa debe ser compartida $y$, en segundo lugar, para perpetuar la influencia helénica del cuidado de sí en la preservación de la salud del cuerpo. Despilfarrar comida o dinero no solo atentaba contra el cuerpo individual, sino contra el cuerpo colectivo o social.

\section{El gesto, el cuerpo y lo performativo: Lo femenino y las pasiones en la gnosis clementina}

Aquella epimeleia permite integrar la economía gastronómica con la teológica. La mayoría de las veces el placer engendra en el hombre daño y tristeza, la abundancia de alimento genera en el alma aflicción, olvido y locura $^{44}$. Si el mucho comer, por ejemplo, es ocasión de demencia, ni qué decir de la mala práctica del hombre beodo o borracho. Las heteras, como les llama Clemente a las hetairai o a las prostitutas finas de la antigüedad, no dejan de servirse de aquellas dos artimañas antiguas en el arte de la seducción: el maquillaje y el vino. El teólogo también advierte del nivel de voluptuosidad al que conduce el vino ${ }^{45}$, ofreciendo opiniones particu-

44 Clemente de Alejandría, El pedagogo I. Traducción de Joan Sariol Díaz, 1998, 157.

45 Clemente de Alejandría, El pedagogo I. Traducción de Joan Sariol Díaz, 1998, 165. Clemente no para de ilustrar con ejemplos gráficos la imagen de una borrachera. Lo cual nos remite al Banquete de Platón, dentro del cual todos afirman estar "hechos una sopa", en medio del diálogo, una expresión para decir que han amanecido de resaca. Acá Alcibíades es el ejemplo de la debilidad pueril que sucumbe no solo ante el vino sino ante la seducción, cuando corteja públicamente a su maestro Sócrates, y por otro lado este otro, su maestro, quien no deja de alardear durante 
lares, tanto para el hombre como para las mujeres: "Al fermentar el vino, los senos y los órganos sexuales se excitan impúdicamente y se hinchan, firme anuncio de la fornicación ${ }^{46 "}$.

También menciona a las mujeres que seductoramente muestran demasiado el cuello para escanciar las bebidas abriendo la boca de forma desproporcionada e inclusive lanzan eructos como los hombres, o peor, como los esclavos y se dejan arrastrar por una vida voluptuosa ${ }^{47}$. Como se ha mencionado, el perfume debe ser objeto de profunda vigilancia porque conduce a la libido y puede llevar a los hombres a consumar actos fuera de la razón. Dentro de esa economía en los usos del cuerpo, tanto el perfume como el aceite, acompañan

todo el diálogo de su capacidad de ingerir vino sin inmutarse o sin perder su cordura en el comportamiento. El vino y la borrachera es parte del simposio para Platón, solo motivo de exhortación cuando el vino atenta contra la salud del cuerpo, pero no porque atraiga pecado alguno. Mucho de esta filosofía está presente en Clemente, en medio de ese temor por agradar al pedagogo y su logos, se sigue reflejando el cuidado de sí cuando arremete contra aquellos que llama desgraciados, para quienes la vida no es más que fiesta, embriaguez, baños, vino puro, orinales, inercia y bebida. "Así puede verse a algunos de ellos medio borrachos, tambaleándose, llevando coronas en el cuello, como las urnas funerarias, escupiéndose mutuamente vino, so pretexto de brindar a su salud. A otros, puede vérselos completamente ebrios, sucios, pálidos, con la mirada lívida, y añadiendo por la mañana una nueva embriaguez sobre la del día anterior".

46 Clemente de Alejandría, El pedagogo I. Traducción de Joan Sariol Díaz, 1998, 160.

47 Clemente de Alejandría, El pedagogo I. Traducción de Joan Sariol Díaz, 1998, 172. el tratamiento adecuado del cabello. El carácter performativo de cada acto, de cada gesto, de cada atuendo no debe salirse del orden armónico que piensa el alejandrino, por ejemplo, a menudo recuerda a Jenofonte cuando criticaba el ocultamiento de la belleza natural de las mujeres a través del maquillaje. Clemente actúa igual que el filósofo socrático, inclusive en sintonía con Ovidio y su tratado sobre la cosmética del rostro femenino.

Clemente, como varón de su época es androcéntrico, sin embargo, otro criterio valioso para comprender su postura sobre el ornato es la crítica a la vanagloria: de nada sirve embellecerse, si no se practica la bondad en primer lugar, y si se practica la vanagloria en segundo lugar. El alejandrino critica, a través de una descripción de Alexis el cómico, cómo algunas prostitutas nunca están a gusto con su apariencia. La ilustración es pintoresca:

¿Por casualidad es baja? Corcho en sus suelas se cose, ¿es alta? Lleva un calzado ligero, $\mathrm{y}$ al andar echa su cabeza sobre el hombro. Así disminuye su altura. ¿No tiene caderas? Se las cose debajo de su vestido, de suerte que ellos al verla claman: ¡Hermosas nalgas! ¿Tiene el vientre grande? Coloca unos pechos de esos que llevan los cómicos. Enderezándolos con palos, la grasa de su vientre elimina, ¿tiene las cejas pelirrojas? Se las pinta de negro. ¿se han puesto morenas? Se untan cera 
blanca. ¿tienen la piel demasiado blanca? Se aplica ungüentos. ¿tiene alguna parte del cuerpo hermosa? La muestra al desnudo. ¿Tiene hermosa dentadura? Se ve forzada a reír, para que los mirones presentes puedan apreciar la hermosura de su boca. Y si su sonrisa no agrada, pasa el día con una delgada rama de mirto en los labios, para contraer su boca con sonrisas, quiera o no quiera $^{48}$.

La crítica a la vanagloria del ornato no queda ahí, sino que acusa de afeminamiento a aquellos hombres que se cortan el cabello cual golfos y prostitu$\operatorname{tas}^{49}$. Si bien, el autor crítica el extremo ornato del cabello también en los hombres, no se puede decir que sea el largo del cabello en sí lo que le parece intemperante, sino su excesivo adornamiento, quizá porque lleva a alejarse de los asuntos más relevantes, y porque podrían conducir a la creación de una persona o ciudadano superficial. Dice el autor del siglo II: "Entre los pueblos, los celtas y los escitas llevan largas melenas, pero no se adornan. El hermoso cabello del bárbaro tiene un algo de temible, y el rubio de su pelo amenaza guerra, por ser dicho color afín a la sangre ${ }^{50}$ ". Si se escudriña con mayor acribia el pensamiento clementino, se pueden descubrir ciertos

48 Clemente de Alejandría, El pedagogo III. Traducción de Joan Sariol Díaz, 1998, 268.

49 Clemente de Alejandría, El pedagogo I. Traducción de Joan Sariol Díaz, 1998, 274.

50 Clemente de Alejandría, El pedagogo III. Traducción de Joan Sariol Díaz, 1998, 282. matices, que llevan a diferentes niveles de análisis. El alejandrino es, sin duda, un pensador polivalente. A veces Clemente deja de ser un filósofo cristiano y se convierte en el predicador más recalcitrante y kerigmático cuando llega a expresiones como: ¡Al infierno la prostitución! pero más adelante da una bella descripción sobre los amantes de la lujuria:

Mas estas mujeres se deleitan en compañía de afeminados; y una turba de depravados, de lengua desenfrenada, invade los hogares, impuros de cuerpo e impuros por sus palabras; viriles cuando se trata de servicios licenciosos, servidores de adulterio, que ríen a carcajadas y cuchichean; olfatean todo lo que despide lujuria, intentan deleitar con palabras y gestos impúdicos, y provocan la sonrisa que desemboca en fornicación ${ }^{51}$.

Los jóvenes son impetuosos y calientes por dentro, por eso deben recluirse a la ingesta de agua. Esta idea del calor o aphros asociada al fuego de la sexualidad es una creencia arcaica presente en filósofos y médicos como Sorano o Galeno, por lo tanto, no es buena idea agregar bebida caliente a un cuerpo también caliente. Esta armonía de los líquidos sin duda es otra herencia estoica.

\footnotetext{
51 Clemente de Alejandría, El pedagogo III. Traducción de Joan Sariol Díaz, 1998, 282.
} 
Clemente se ocupa por la economía del agua en el cuerpo. Una armonía pitagórica, si se quiere, en torno la humedad del cuerpo. "En efecto, escupir a cada momento, sonarse y correr a causa de las excreciones es señal de intemperancia, pues denota un exceso de líquido en el cuerpo ${ }^{52}$ ". Es notable que, a menudo, las faltas a la moral están asociadas a cuestiones sanitarias. Otra herencia de escuelas filosóficas como las pitagóricas, platónica o socrática, sobre todo en los textos de Jenofonte. Así como el exceso de aphros o de fuego interno atenta contra la moderación de las pasiones, asimismo como hemos visto, sucede con el exceso de agua. Es posible, entonces, hablar de un cultivo de sí basado en el cuidado, aún en el mismo Clemente. Y acá viene lo polémico, pues ahí donde Jenofonte o Plutarco ofrecen sentencias en torno al comportamiento, Clemente sigue un camino semejante, pero ya cristianizado, ya no tanto en aras al cuidado del cuerpo sino en razón de la práctica religiosa en torno a una voluntad divina. Lo cierto es que, a pesar de esta teologización de los afectos, el cuidado de sí sigue estando palpable.

52 Clemente de Alejandría, El pedagogo II. Traducción de Joan Sariol Díaz, 1998, 161.

\section{Conclusiones: Una ocasión para la risa, la festividad y la voluptuosidad en la gnosis clementina}

Como ya se ha dicho, la musicalidad es parte importante del pensamiento clementino, se detiene para discernir, si esta o aquella melodía, son saludables y permitidas por el logos, lo mismo pasa con los intrumentos musicales. Los pasajes sobre los instrumentos son bellísimos y reflejan un oído atento a cada estilo musical de la época, que a un tiempo testifica cómo la música es obra de la corporalidad y su armonía. Hay melodías que conducen al erotismo y a la embriaguez, mediante aquel antiguo canto llamado himeneo, que no es más que un encomio nupcial, y que levanta las pasiones más irracionales, las cuales se sitúan fuera de la comunidad. Los ejemplos anteriores permiten colegir cómo cada afecto o gesto se asocia o desemboca en la molicie de la concupiscencia, ya sea el tomar vino, usar perfumes o adornos, reír a carcajadas o bien escuchar ciertas melodías que excitan la voluptuosidad.

No es que la música sea prohibida dentro del esquema de vida común clementina, sino que requiere de un mesurado examen, porque algunas melodías incitan al desorden; otras, al parecer blandas, más bien afeminan la vista y el oído. Y, ya por afeminarse los sentidos, dirá el teólogo, se encuentra el ciudadano más cerca de la intemperancia 
y el desenfreno, lo mismo pasa con las melodías aparentemente blandas que no son más que ritmos hechiceros, los cuales arrastran con pasión a un género de música licenciosa y malsana ${ }^{53}$.

Clemente, como hombre común de su época tiene muy marcada la diferente condición de ser varón y mujer en el mundo de la antigüedad, en una sociedad donde el afeminamiento no es visto con buenos ojos por algunos gobernantes romanos, algunos de ellos estoicos, ni que decir la influencia paulina, recogida del patriarcalismo y rabinismo judío. La influencia de las Quaestiones Convivales de Plutarco en torno al afeminamiento es muy marcada en Clemente. Una reflexión en conjunto de estas obras y sistemas de pensamiento permite rastrear orígenes e influencias sobre el género en la sociedad occidental. De entrada, que el varón tuviera comportamientos que pertenecen a las mujeres era motivo de exhortación. No se debe confundir al varón afeminado con el homosexual, pues el afeminamiento, aunque por lo general se asociaba al homosexual, hace alusión a algo mucho más amplio. Atender enfermos o curar heridas, servir la mesa, todo eso afeminaba al varón, así pues, no solo era un problema que amara a otro varón desde el punto de vista cristiano, sino que desacatara su lugar como hombre, desde el punto

53 Clemente de Alejandría, El Pedagogo II. Traducción de Joan Sariol Díaz, 1998, 181. de vista helénico. Una barba rasurada, por ejemplo, sería motivo de vergüenza, para el pensamiento clementino, muy acorde al ideal de hombre griego. En esa economía del rostro, barba y bigote eran símbolo de dignidad, respeto y hombría.

Con todo, la fiesta siempre aparece toda vez que Clemente refleja la pasión humana por lo lúdico. A pesar de su encarecido exhortar en torno a las fiestas paganas, él mismo cae en la festividad humana cuando invoca la trompeta $^{54}$ y la misma arpa en nombre de Dios, además ofrece una bella metáfora donde la lengua es el arpa del Señor y la boca es comparada con una cítara. "Alabadle con el tambor y con un coro", replica Clemente citando el Salmo 150. Una afirmación tal no es más que la testificación de una corporalidad que sale y entra dentro de lo festivo, viendo una embriaguez como licenciosa, pero la otra como pura. La primera, la del vino; la segunda, la del encomio casi dionisíaco a la figura, sea cual sea, del dios cristiano. Dentro del estoicismo clementino y su aparente rigidez en torno a lo orgiástico también hay fiesta. La fiesta es una de las formas de resucitar la carne, llevada a cabo a través de la piel resonante, una forma de Clemente para referirse al tambor $^{55}$. En Clemente, tanto el cuer-

54 Clemente de Alejandría, El pedagogo II. Traducción de Joan Sariol Díaz, 1998, 181.

55 Clemente de Alejandría, El pedagogo II. Traducción de Joan Sariol Díaz, 1998, 182. 
po del pagano como el del cristiano bailan, y no pareciera hallarse una diferencia abismal entre una festividad y otra.

Mientras Clemente escribe su Pedagogo, el ambiente es aún demasiado heterogéneo en la antigua Roma, dando cabida no solo para la tragedia, sino para el simposio y el carnaval. Las Liberalia se practicaban sin impedimentos como culto en honor al falo, solo por citar un ejemplo y los desnudos pompeyanos eran de sobra conocidos por los ciudadanos, a menudo asociados a la prostitución. A pesar del llamado a la temperancia, ese carácter festivo existe en el teólogo alejandrino, aunque no parezca. Cristo gustaba de prestar atención para oír este sereno divertirse de sus santos sobre la tierra: celebrando festividades a Dios... pues a esto juega Júpiter ${ }^{56}$.

Es posible ver más allá de su rigurosidad, cuando el mismo dice: "Debemos ser graciosos sí, pero no bufones" ${ }^{\prime 57}$. Pareciera sorprendente que el humor es también parte del logos

Diferenciar las otras citas entre libro I, II y III. Así pues, en campaña, los habitantes del Tirreno utilizan la trompeta; los arcadios, la zampoña, los sicilianos, el arpa; los cretenses, la lira; los lacedemonios, la flauta ordinaria; los tracios, el cuerno; los egipcios, el tambor, y los árabes, los platillos. Nosotros, en cambio, no utilizamos más que un instrumento, el Logos pacífico, con el que honramos a Dios.

56 Brown, Cuerpo y Sociedad..., 186.

57 Clemente de Alejandría, El Pedagogo II. Traducción de Joan Sariol Díaz, 1998, 186. clementino, sobre todo como él dice, cuando un joven es demasiado tímido, se le enseña a través de la broma, siempre y cuando sea esta parte del logos de la sabiduría y dirigida preferiblemente por la enseñanza de un anciano. No es posible hablar de represión alguna como tesis para comprender a los padres de la Iglesia, sobre todo cuando entre ellos existieron sendas diferencias. Las posturas de Clemente frente al mundo pagano, sus costumbres y cultos fue mucho más flexible que la de un Tertuliano.

Sin embargo, No por el hecho de que el hombre sea un animal que ríe, debe uno reirse de todo; ni porque el caballo relinche, debemos relinchar siempre $^{58}$. Una definición tal sobre el ser humano como animal que ríe no podría ser más aristotélica. Por otro lado, Clemente prefiere la erubescentia o la ruborización antes que la risa a carcajadas, el tema de la erubescentia será uno de los primeros indicios de la confesión. Antes del confesionario, es posible encontrar la confesión entre los propios habitantes, basada en la pena o vergüenza, para luego pasar a los manuales de confesión dentro de los cuales el cuerpo tiene que decirse a sí mismo, confesarse con su entorno social. El tema de la vergüenza es parte de esta animalidad, si se quiere hominidad, de la cual el alejandrino está consciente.

58 Clemente de Alejandría, El Pedagogo II. Traducción de Joan Sariol Díaz, 1998, 186-7. 
Dentro de este tema de lo humorístico, insiste en aquella armonía del cuerpo de la que hemos hablado.

El cuerpo que carcajea pierde su armonía, pero no solo se trata de eso, sino que a través de la risa entra la molicie. Por lo tanto, repite la idea aristotélica del humano como animal racional. La sonrisa relajada es la señal de un hombre virtuoso y prudente, no así el hombre que ríe mucho, pues actúa como quien corteja a aquella otra dama risueña, es decir, la prostituta. El que se sonroja denota sentimiento y humildad, moderación, pero quien ríe a pesar de la falta es un cruel.

Clemente no para de citar influencias de toda la amplia literatura helénica, va de Platón a Plutarco, vuelve sobre la Ilíada o Sófocles, para referirse a un asunto y a otro. Por ejemplo, no deja de sentenciar a los muchachos ante su posible afeminamiento, pues es propio del sabio la mesura en la voz, e impedir la rapidez y la profusión, ni hablar en exceso en la conversación, ni charlar atolondradamente ${ }^{59}$. Aunque, por otro lado, en sintonía con Sófocles alaba que el silencio es una virtud de las mujeres.

Sobre el hombre, advierte la mesura al sentenciar "un hombre lenguaraz

59 Clemente de Alejandría, El Pedagogo II. Traducción de Joan Sariol Díaz, 1998, 197. es un peligro para su ciudad ${ }^{60}$ ", dejando ver otra preocupación por mantener la vida común, pues esta debe librarse del exceso en la lengua. No es tiempo aún de los manuales de confesión, sino de una ética del arte de usar la palabra, en tiempo, medida, tono, intensidad e intención. Ni muy hablador ni muy silencioso, dirá Clemente. Las construcciones e imaginarios sobre la antropología humana en torno al género son sugerentes en Clemente y permiten encontrar raíces cristianas en nuestra sociedad actual.

En conclusión, el elogio de la sencillez en Clemente señala hacia la capacidad de la persona humana de hacerse divina. Hacerse como dios no implica acá, ser el dueño del oro y la plata, sino renunciar a las riquezas como lo hizo el Pedagogo o el Logos, es decir Cristo. "El hombre es, por naturaleza, un animal excelso y majestuoso que busca lo bello y a los placeres civilizados ${ }^{61}$ ". El hombre divino, por lo tanto, el hombre bello, es quien elogia la sencillez. El placer civilizado ilustraba una serie de formas heterogéneas de vida común, por eso es oportuno hablar de una administración de las pasiones y de los placeres en Clemente. En efecto, como varón de su época sus concepciones nos podrían parecer chocantes, lo valioso de

60 Clemente de Alejandría, El Pedagogo II. Traducción de Joan Sariol Díaz, 1998, 197.

61 Clemente de Alejandría, El Pedagogo III. Traducción de Joan Sariol Díaz, 1998, 293. 
estudiar a un autor de esta naturaleza es el testimonio de primera mano de lo que se ha conocido como el mundo de la antigüedad tardía. La gnosis de Clemente debe comprenderse más allá de un ejercicio de comprensión del cosmos; es, más bien, como una serie de ejercicios de ética basados en el cuidado de la salud de la carne, el elogio a la sencillez, la respuesta cristiana a la aristocracia y la pomposidad romana, $\mathrm{y}$ el sophron bios o vida temperante.

Pensar a Clemente como un embajador de una regla monástica o como un moralista de la etiqueta supone una lectura limitada, poco creativa y apresurada, de su pensamiento filosófico y teológico. Sin duda, a la par de aquella aparente obstinación por la etiqueta, nos ofrece un compendio de fuentes para comprender que en aquel cristianismo temprano convivían muchas expresiones corporales que han desembocado en maneras de vivir y construir las performatividades en la actualidad, tanto el papel de lo femenino, el atrevimiento de las hetairas o prostitutas, los afeites y perfumes del cuerpo, las vestimentas y atuendos de los varones, las francachelas de los borrachos, el amor poético entre los amantes, la polifonía de las expresiones musicales, los gustos en la comida y las prácticas sexuales gnósticas basadas en el encuentro sexual. Todo ello nos es conocido gracias al trabajo del alejandrino y su compendio literario, enfrentado muchas veces ante el piadosísimo encratita por su negativa al uso del vino o al matrimonio. Es posible hablar también de un Clemente comiendo, manteniendo conversaciones, andando con pasos vivos por los prados bien podados de una villa helenística de las afueras, incluso, en ocasiones retirándose discretamente al lecho con su esposa ${ }^{62}$. A pesar de su moral cristiana, nos permite imaginar y construir saberes que nos lleven a seguir comprendiendo las dinámicas del cuerpo y sus pasiones con mayor alacridad.

\section{Bibliografía}

Brown, Peter. El mundo de la Antigüedad Tardía. Prólogo de José Enrique Ruiz-Domenech y traducción de Antonio Piñero. Madrid: Gredos, 2012.

Brown, Peter. El cuerpo y la sociedad. Los hombres, las mujeres y la renuncia sexual en el cristianismo primitivo. Traducido del inglés por Antonio Juan Desmonts. Barcelona: Muchnick editores, 1993.

Brown, Peter y Thébert, Yvon. Historia de la vida privada. Tomo I. Imperio Romano y Antigüedad Tardía. Bajo la dirección de Phillipe Ariès y Georges Duby. Madrid: Taurus, 1990.

Celso. El discurso verdadero contra los cristianos. Introducción, traducción

62 Brown, El cuerpo y la sociedad..., 176-7. 
y notas de Serafín Bodelón. Madrid: Alianza, 2009.

Clemente de Alejandría. Stromata I. Conocimiento y religión. Introducción, traducción y notas de Marcelo Merino Rodríguez. Fuentes Patrísticas 7. Madrid: Ciudad Nueva, 1996.

Clemente de Alejandría, Stromata II-III. Fuentes patrísticas 10 . Conocimiento religioso $y$ continencia auténtica. Introducción, traducción y notas de Marcelo Merino Rodríguez. Madrid: Ciudad Nueva: 1998

Clemente de Alejandría. El pedagogo. Introducción de Ángel Castiñeira, traducción y notas por Joan Sariol Diaz. Madrid: Gredos, 1998

Filóstrato. Vida de Apolonio de Tiana. Traducción, introducción y notas de Alberto Bernabé. Biblioteca Clásica Gredos 18. Madrid: Gredos, 2008
Foucault, Michel. Historia de la sexualidad IV. Las confesiones de la carne. Edición de Frederic Gros y traducción de Horacio Pons. Madrid: Siglo XXI, 2019

Juliano. Contra los galileos. Cartas y fragmentos. Testimonios. Leyes. Introducción, traducción y notas por José García Blanco y Pilar Jiménez Gazapo. Madrid: Gredos, 1982

Montserrat Torrents, José. Los gnósticos I. Biblioteca Clásica Gredos, 59. Madrid: Gredos, 1983.

Montserrat Torrents, José. Los gnósticos II. Biblioteca Clásica Gredos, 60. Madrid: Gredos, 1983

Piñero Antonio, Montserrats Torrents José y García Bazán, Francisco. Textos gnósticos. Biblioteca de Nag Hammadi I. Tratados filosóficos y cosmológicos. Madrid: Trotta, 2007. 